\title{
Analisis Strategi Marketing Public Relations Dalam Meningkatkan Loyalitas Customer Sofyan Hotel (Studi Deskriptif Pada Sofyan Hotel Cut Meutia Menteng Jakarta Pusat)
}

\author{
${ }^{1}$ Audia Saraswati, ${ }^{2}$ Diana Prihadini \\ ${ }^{1 \& 2}$ Institut Ilmu Sosial dan Manajemen STIAMI \\ Program Studi Manajemen Komunikasi - Fakultas Ilmu Sosial dan Ilmu Manajemen \\ Email: ${ }^{1}$ audia.saras05@gmail.com, ${ }^{2}$ dianahantoro@yahoo.com
}

Keywords:

Marketing Public

Relations Strategy, Public

Relations, Customers

Loyalty

The intense competition in the Indonesian tourism industry and the number of business hotels in Jakarta that offer more modern services and facilities make customers disloyal. In this situation, companies need to make a special strategy to maintain and increase customer loyalty. Based on these problems, this research focuses on the Marketing Public Relations strategy in increasing customer loyalty. This research is qualitative research with a descriptive analysis method, data collection techniques in observation, interviews, documentation, and literature study. This research is the Public Relations of Sofyan Hotel Cut Meutia in carrying out the marketing public relations strategy activities using six of the seven marketing public relations instruments and using the pull, push, and pass strategy according to Kottler and Keller. These include publications in print and online media, identity media, events, news, sponsorship, and corporate social responsibility. The suggestions given in this study to Sofyan Hotel Cut Meutia are maximizing Marketing Public Relations activities by making innovations, improving hotel services and facilities to customers.
\end{abstract}

\section{PENDAhuluaN}

Pesatnya pertumbuhan industri perhotelan di Indonesia khususnya di DKI Jakarta merupakan peluang bagi para pelaku bisnis. Hal tersebut ditandai dengan munculnya berbagai ragam hotel yang berlomba-lomba untuk menjadi pemenang. Salah satu industri hotel yang merasakan dampak dari persaingan ketat ini adalah hotel syariah atau bisa disebut dengan hotel halal.

Sofyan Hotel Cut Meutia yang berada di Jakarta Pusat tepatnya di Kecamatan Menteng merupakan salah satu diantara hotel syariah yang mengalami dampak dari ketatnya persaingan bisnis perhotelan. Sofyan Hotel Cut Meutia didirikan pada tahun 1992, secara geografis letaknya berada di pusat ibukota, tepatnya di Jalan Cut Meutia No 9, Jakarta Pusat, sofyan Hotel memiliki ciri khas unik diantaranya mengusung konsep syariah atas dasar nilai-nilai syariah Islam, Makanan dan minuman yang disediakan pun sudah mendapat izin halal yang telah bersertifikasi MUI, sehingga konsumen tidak perlu khawatir karena menu makanan dan minuman yang disajikan sudah halal, selain itu disetiap kamar juga disediakan perlengkapan shalat dan kitab suci Al-quran.

Ketatnya persaingan bisnis di bidang perhotelan membuat Sofyan Hotel Cut Meutia harus berpikir keras untuk memiliki strategi khusus, unik dan tepat, komunikasi yang baik dan tepat sasaran menjadi salah satu kunci strategi marketing public relations dimana strategi ini sebagai alat pemasaran yang digunakan oleh Sofyan Hotel Cut Meutia, setiap hotel pasti memiliki strategi tersendiri yang membedakan dengan bisnis hotel lainnya, agar menghindari dari kerugian. memasarkan produk dan jasa adalah kegiatan komunikasi yang membutuhkan strategi. bukan sekedar menyampaikan pesan mengenai produk dan jasa kepada publik. tetapi juga harus memiliki muatan pesan yang tepat, menarik, mudah dimengerti, program yang tepat dan media yang sesuai dengan target, sehingga semua bentuk komunikasi yang ingin disampaikan bisa berjalan dengan efektif. 
Ada beberapa kendala yang dihadapi oleh public relations Sofyan Hotel Cut Meutia dengan menjalankan strategi marketing public relations yaitu menangani komplain seperti komplain fasilitas kamar dan servis hotel, membangun relasi yang baik dengan customer, mengorganisir kegiatan maupun event PR, Praktisi PR Sofyan hotel Cut Meutia juga perlu belajar untuk mencari peluang bagaimana caranya sofyan hotel mendapatkan manfaat dari aktivitas public relations. Sofyan hotel pun harus terus melakukan inovasi dengan menggunakan alat Marketing Public Relations dan 3 taktik strategi marketing public relations yaitu strategi pull, push dan pass guna untuk menarik minat pelanggan, dalam memasarkan jasanya dan menjalankan fungsi eksternalnya Marketing Public Relations Sofyan Hotel Cut Meutia melaksanakan kegiatan-kegiatan yang mendukung kegiatan pemasaran seperti promosi melalui internet dan media sosial, publisitas hotel melalui media cetak, dan media online, brosur, flayer, digital ADS (OTA), bekerjasama dengan public figure, berkolaborasi dengan komunitas atau brand untuk membuat suatu kampanye maupun event, menjadi sponsorship dalam mendukung sebuah event dan ikut serta dalam acara bazaar.

Mempertahankan dan meningkatkan loyalitas customer sangat penting untuk perusahaan, karena akan semakin sulit jika perusahaan hanya mengandalkan customer baru. Kesulitan perusahaan mendapatkan customer baru dapat dikarenakan pada faktor biaya yang cukup besar. Hal ini menjadikan stategi Marketing Public Relations sebagai jalan keluar untuk meningkatkan loyalitas customer. Melihat fenomena persaingan ketat bisnis hotel khususnya hotel syariah, maka peranan Marketing Public Relations Sofyan Hotel Cut Meutia membuat strategi marketing public relations yang berbeda untuk meningkatkan loyalitas customer agar dapat bersaing dengan hotel konvensional menjadi penting.

Berdasarkan uraian latar belakang, maka tujuan penelitian ini adalah untuk menganalisis Strategi Marketing Public Relations Dalam Meningkatkan Loyalitas Customer Sofyan Hotel (Studi Deskriptif Pada Sofyan Hotel Cut Meutia Menteng Jakarta Pusat).

\section{KERANGKA TEORITIS}

\section{Public Relations}

Definisi public relations menurut International Public Relations Association (IPRA:1978), public relations adalah fungsi manajemen yang khas dan mendukung pembinaan, pemeliharaan jalur bersama antara organisasi dengan publiknya, menyangkut aktivitas komunikasi, pengertian, penerimaan dan kerja sama, melibatkan manajemen dalam menghadapi permasalahan, membantu manajemen untuk mampu menanggapi opini publik, mendukung manajemen dalam mengikuti dan memanfaatkan perubahan secara efektif, bertindak sebagai sistem peringatan dini dalam mengantisipasi kecenderungan penggunaan penelitian serta teknik komunikasi yang sehat dan etis sebagai sarana utama (Ruslan, 2016:16).

\section{Tujuan Public Relations}

Tujuan public relations menurut Ruslan (dalam Suryanto, 2015:431) memberikan beberapa tujuan public relations adalah mengembangkan citra perusahaan yang positif untuk publik eksternal dari konsumen, mendorong tercapainya saling pengertian antara publik dan perusahaan, mengembangkan sinergi fungsi pemasaran dengan public relations, memperkenalkan merek dan membangun pengetahuan merek secara efektif, serta mendukung bauran pemasaran.

\section{Strategi Marketing Public Relations}

Kotler (Ali, 2017:42) menyebutkan tujuan dari Marketing Public Relations ini untuk menampilkan pola how to service of excellent marketing dalam upaya mempertahankan loyalitas pelanggan. Proses Planning, organizing, Action dan Controlling dari program-program yang dapat merangsang pembelian dan kepuasan konsumen melalui komunikasi yang dipercaya dan berkaitan dengan kebutuhan, keinginan, perhatian, dan kepentingan konsumen.

Kotler dalam buku Ruslan (2016:246) mengatakan konsep Marketing Public Relations secara garis besar dilakukan melalui tiga taktik atau three ways strategy untuk melaksanakan program dalam mencapai tujuan, yaitu Pull, Push, Pass. Strategi Pull, merupakan strategi untuk menarik, 
menyelanggarakan komunikasi timbal balik dua arah yang didasari oleh informasi dan pesan-pesan yang dapat dipercaya, diharapkan dapat menciptakan kesan-kesan positif terhadap lembaga yang diwakilinya.

Strategi Push, merupakan strategi untuk mendorong dalam hal pemasaran atau merangsang dalam hal pembelian dan sekaligus dapat memberikan nilai-nilai atau kepuasan bagi pelanggan yang telah menggunakan produknya. Strategi Pass, merupakan strategi sebagai upaya mempengaruhi atau menciptakan citra publik yang menguntungan ditimbulkan melalui berbagai kegiatan (breakthrough the gate-keepers), dan partisipasi dalam kegiatan kemasyarakatan atau tanggung jawab sosial, serta kepedulian terhadap masalah-masalah yang berkaitan dengan kondisi sosial dan lingkungan hidup.

\section{Marketing Public Relations}

Philip kottler dalam Ruslan (2016:245) menjelaskan konsep marketing public relations yaitu marketing public relations adalah sebuah proses perencanaan dan pengevaluasian program yang merangsang penjualan dan pelanggan. Hal tersebut dilakukan melalui pengkomunikasian informasi yang kredibel dan kesan-kesan yang dapat menghubungkan perusahaan, produk dengan kebutuhan serta perhatian pelanggan.

Menurut Kotler \& Keller (Sari, 2017: 46-47) strategi Marketing Public Relations didukung kegiatan-kegiatan dari tujuh alat Marketing Public Relations yang berhubungan dengan customer, diantaranya yaitu pertama, publikasi (publications), dapat digunakan dalam perluasan produk untuk mempengaruhi dan menarik sasaran. Bentuk publikasi dapat berupa laporan tahunan, artikel, brosur, majalah dan materi audio-visual. Kedua, media identitas (identity media). Perusahaan perlu membuat identitas agar bisa dikenal oleh masyarakat dengan mudah, Misalnya logo perusahaan, alat-alat tulis, brosur, tanda, formulir perusahaan, kartu nama, bangunan, dan seragam.

Ketiga, acara (event). Dengan mengadakan suatu acara khusus, perusahaan dapat menarik perhatian mengenai produk baru atau kegiatan perusahaan, seperti mengadakan acara seminar, pameran, kompetisi, kontes dan ulang tahun dari barang itu supaya dapat menjangkau masyarakat luas. Keempat, berita (news). Salah satu dari tugas utama dari Public Relations yaitu membuat isi suatu berita untuk membuat media-media tertarik meliput dan memuat berita siaran pers dan hadir dalam konferensi pers.

Kelima, pidato (speech). Semakin tinggi kebutuhan perusahaan untuk dapat menjawab setiap keperluan masyarakat dengan menjawab pertanyaan yang diajukan oleh media atau memberikan pengarahan di asosiasi penjualan dan pertemuan yang bertujuan untuk membicarakan soal penjualan dapat membangun citra perusahaan. Keenam, berperan serta dalam aktivitas sosial (public service activity). Perusahaan dapat membangun citra yang positif dengan cara menyumbang uang atau memberikan kontribusi dalam hal-hal yang berkaitan dengan isu-isu sosial maupun lingkungan. Ketujuh, sponsorship. Perusahaan dapat memasarkan barang melalui pemberian sponsor dalam acara olahraga atau acara kebudayaan yang bermanfaat bagi keberlangsungan produk maupun jasa.

\section{Loyalitas Pelanggan}

Pengertian Loyalitas menurut Griffin dalam buku Puspaningrum (2017:31) Loyalitas didefinisikan sebagai pembelian tidak acak yang dinyatakan seiring waktu oleh unit pengambilan keputusan. Selanjutnya, Griffin (2016:31) menjelaskan karakteristik pelanggan yang loyal memiliki karakter melakukan pembelian secara berulang secara teratur, membeli antarlini produk dan jasa, mereferensikan kepada orang lain, dan menunjukkan kekebalan terhadap tarikan dari pesaing

\section{METODE PENELITIAN}

Jenis pendekatan pada penelitian ini adalah pendekatan kualitatif deskritif, dengan teknik pengambilan data melalui observasi, dokumentasi (Sugiyono, 2015:329) dan studi pustaka. Teknik analisis data yang digunakan penelitian ini dilakukan melalui tahapan pengumpulan data dan fakta mentah dilapangan, setelah itu data akan direduksi dan dituangkan dalam bentuk uraian atau paparan yang lengkap sesuai dengan topik permasalahan, selanjutnya data disajikan dengan cara hasil wawancara dideskripsikan yang dituangkan dalam bentuk teks naratif, lalu langkah terakhir adalah penarikan kesimpulan dengan temuan bukti-bukti kuat yang didapat dari hasil penelitian untuk menjawab pertanyaan penelitian. 


\section{HASIL PENELITIAN DAN DISKUSI}

\section{Strategi Marketing Public Relations}

Kotler (dalam Ali, 2017:42) menyebutkan tujuan dari strategi marketing public relations perlu memperhatikan pola how to service of excellent marketing dalam upaya mempertahankan loyalitas pelanggan. Hal ini telah dilaksanakan oleh PR Sofyan Hotel Cut Meutia dalam aktivitas strategi marketing public relations melalui program-program PR yang telah dilakukan dan dijalankan secara rutin dengan sangat baik dengan cara menggunakan ketiga taktik strategi pull, strategi push dan strategi pass menurut Ruslan (2016: 246).

Strategi pull yang dilakukan Sofyan Hotel Cut Meutia adalah melalui pesan-pesan positif, sehingga dapat dapat menciptakan kesan-kesan positif terhadap Sofyan Hotel Cut Meutia. Strategi pull dilakukan dengan aktif melalui publikasi di media online seperti update konten menarik, mengadakan giveaway voucher, kuis, kompetisi, games dan repost foto-foto customer di instagram sofyan hotel, memasang iklan di google ads, OTA dan media cetak memasang banner, flyer, brosur dan aktivasi di dalam Hotel, serta kerjasama dengan media online dan media cetak untuk membantu mempublikasian Sofyan Hotel Cut Meutia. Strategi Pull adalah upaya untuk mendorong pemasaran atau merangsang pembelian dan sekaligus dapat memberikan nilai-nilai kepuasan bagi pelanggan yang telah menggunakan produk dan jasa Sofyan Hotel Cut Meutia.

Strategi Push Sofyan Hotel Cut Meutia adalah dengan mengadakan promo kamar, promo special menu, promo meeting room, promo wedding package yang berbeda setiap bulannya di moment dan hari besar seperti bulan ramadan, hari raya kemerdekaan RI, idul fitri, idul adha, tahun baru. Selain itu, Sofyan Hotel Cut Meutia juga melakukan direct marketing seperti door to door, sales call dan whatapp blast, promosi lewat media cetak seperti brosur, pamflet dan flyer, serta mempromosikan Sofyan Hotel dari bazaar, event dan pameran yang di ikuti oleh Sofyan Hotel.

Sedangkan untuk strategi Pass digunakan Sofyan Hotel Cut Meutia untuk upaya mempengaruhi, menciptakan citra publik yang menguntungan, partisipasi dalam kegiatan kemasyarakatan atau tanggung jawab sosial. Strategi pass lain yang dilakukan Sofyan Hotel Cut Meutia adalah dengan melakukan kegiatan CSR seperti donor darah, bekerjasama dengan Baznas sebagai pihak ketiga antara Sofyan Hotel dengan masyarakat, mengadakan santunan anak yatim, mini talkshow dan seminar di dalam Sofyan Hotel, berkolaborasi dan bekerjasama dengan brand, influencer dan komunitas, serta mengadakan maupun turut ikut serta berkolaborasi dalam acara pameran, event dan bazaar.

\section{Alat Marketing Public Relations}

Pelaksanaan strategi Marketing Public Relations Sofyan Hotel Cut Meutia yang dilakukan PR Sofyan Hotelpun tidak terlepas dari tujuh Alat Marketing Public Relations sebagai pendukung strategi Marketing Public Relations yang digunakan yang dikemukakan oleh Kotler dan Keller (dalam sari, 2017: 46-47). Alat marketing public relations yang dilakukan Sofyan Hotel Cut Meutia diantaranya yaitu:

a. Publikasi. Dalam menyebarkan informasi dan pesan kepada publik, publikasi yang digunakan Sofyan Hotel Cut Meutia diantaranya melalui media cetak seperti brosur, pamphlet, flyer, publikasi di media online seperti website Sofyan Hotel, google ads dan online travel agencies (OTA), serta memanfaatkan Instagram. Sofyan Hotel Cut Meutia juga kerjasama dengan media online atau offline, dan influencer untuk membantu mempublikasikan Sofyan Hotel dalam bentuk artikel atau youtube video.

b. Acara. Dalam rangka mendongkrak kunjungan tamu, Sofyan Hotel Cut Meutia mengadakan beberapa acara seperti berkolaborasi dengan brand atau komunitas untuk membuat sebuah event/bazaar/pameran. Membuat acara gathering dengan partners, mini talkshow atau seminar. Bekerjasama dengan berbagai media dan influencer, kegiatan eksternal yang dilakukan rutin dilakukan setiap 2 bulan sekali.

c. Berita. Salah satu kemampuan dan pekerjaan seorang public relations yaitu menulis dan membuat berita. Berita yang dibuat dan disebarkan harus menarik dan unik, sehingga media tertarik dan menerima press release yang diberikan untuk diulasnya di media massa. Sofyan 
Hotel Cut Meutia untuk membuat berita mengenai Soyan Hotel bekerjasama dengan media partner seperti bisnis indonesia, republika, kumparan, detik, halalnews, sharianews, scarfmedia, dsb. News sebagai salah satu bentuk kegiatan marketing public relations digunakan oleh public relations Sofyan Hotel Cut Meutia pada saat peluncuran logo baru Sofyan Hotel tahun 2018. Hal ini dilakukan agar pemberitaan yang diunggah oleh media dapat meningkatkan citra atau reputasi positif dan informasi tersebar luas oleh publik melalui portal media.

d. Media Identitas. Identitas merupakan wujud dan ciri khas perusahaan yang diakui oleh publik internal dan eksternal. Sofyan Hotel memiliki ciri khusus yang digunakan yaitu konsep hotel syariah atau hotel halal, logo, brosur, flyer, seragam karyawan yang tertutup, elemen furniture hotel, id card, member card, in house tv, merchandise, website. Pentingnya media identitas dikenalkan kepada publik agar keberadaan perusahaan diketahui dan diakui oleh publik secara lebih luas. Identitas tersebut dijaga dan dipertahankan oleh Sofyan Hotel agar terus menginspirasi customer dan melakukan inovasi pada berbagai produk dan jasa Sofyan Hotel Cut Meutia demi keberlangsungan hidup perusahaan.

e. Berperan Serta Dalam Aktivitas Sosial. Ikut berperan dalam aktivitas sosial merupakan salah satu upaya dan strategi marketing public relations, karena kegiatan sosial yang dilakukan untuk meningkatkan hubungan baik dan sebagai wujud rasa tanggung jawab sosial Sofyan Hotel kepada masyarakat. Sofyan Hotel melakukan aktivitas sosial seperti donor darah, santunan yatim piatu, menyisihkan sebagian hasil penjualan kepada Baznas untuk dibagikan kepada masyarakat kurang mampu dan kegiatan CSR lainnya. Kegiatan CSR yang dilakukan oleh Sofyan Hotel menimbulkan nilai positif, yaitu trust customer menjadi meningkat dan banyak customer yang tertarik dengan aktifitas terkait dengan donasi.

f. Sponsorship. Sponsorship merupakan salah satu bentuk strategi marketing public relations dan upaya yang digunakan oleh Sofyan Hotel dengan pihak lain. Kegiatan sponsorship ini dapat memberikan keuntungan kepada kedua belah pihak yaitu perusahaan dan penyelenggara event. Kegiatan sponsorship dilakukan Sofyan Hotel Cut Meutia guna menarik minat calon customer maupun customer lama sesuai target market sofyan hotel, jenis-jenis kegiatan event yang disponsori, seperti event halal travel, fashion muslim, lifestyle halal, halal food, sharia property, dan lain. Bentuk sponsorship yang diberikan berupa uang, barter voucher hotel atau barter catering.

\section{Diskusi}

Strategi marketing public relations yang dilakukan public relations Sofyan Hotel Cut Meutia dengan menggunakan teknik komunikasi dan pemilihan media yang tepat, acara atau event yang diselenggarakan secara rutin dalam setiap aktivitas marketing public relations, dan strategi komunikasi yang khusus dan baik kepada customer maupun calon customer, sehingga dapat menumbuhkan daya tarik customer kepada Sofyan Hotel Cut Meutia yang dapat menciptakan rasa kepuasan customer terhadap jasa atau produk Sofyan Hotel Cut Meutia dan dapat meningkatkan loyalitas customer.

Berdasarkan konsep Kotler mengenai strategi pull, strategi push dan strategi pass, telah dilakukan oleh PR Sofyan Hotel Cut Meutia. Diantaranya adalah menciptakan kesan-kesan positif terhadap Sofyan Hotel Cut Meutia, berbagai kegiatan promo hotel, kegiatan corporate social responsibility yang bekerjasama dengan pihak Baznas, Palang Merah Indonesia, Influencer, dan Komunitas.

Strategi marketing public relations yang dilakukan PR Sofyan Hotel Cut Meutia tentunya tidak selalu berjalan dengan lancar, terdapat berbagai hambatan yang menghambat kerja public relations dengan efektif. Beberapa kendala diantaranya yaitu memanage waktu, tenaga, menangani keluhan customer, membangun relasi dengan customer baru dan customer lama, mengorganisir kegiatan event Public Relations, pelayanan yang kurang maksimal, kurangnya fasilitas dan sarana, tingginya kebutuhan dan keinginan dari para customer terhadap Sofyan Hotel Cut Meutia.

Adapun upaya dan solusi yang dilakuan PR Sofyan Hotel dalam menangani kendala yang terjadi dalam menjalankan strategi marketing public relations diantanya meningkatkan aktivitas Cyber PR Sofyan Hotel untuk mendukung strategi pull, push dan pass dan alat marketing public relations. Berupaya untuk mempertahankan dan meningkatkan customer dengan mengikuti perkembangan yang sedang trendy dan mengembangkan pengetahuan staff, manajemen dan pimpinan perusahaan agar terus mengetahui perkembangan pasar. 


\section{SIMPULAN}

Langkah-langkah strategi marketing public relations Sofyan Hotel Cut Meutia pertama meggunakan 6 dari 7 alat marketing public relations, yaitu publikasi, media identitas, acara, berita, berperan serta dalam aktivitas sosial dan sponsorship sebagai pendukung three ways strategy yaitu strategi pull, push dan pass. Strategi pull dilakukan Sofyan Hotel Cut Meutia melalui publikasi dimedia cetak dan media online resmi Sofyan Hotel. Hal ini guna menarik perhatian publik melalui informasi dan pesan-pesan yang dipublikasikan oleh Sofyan Hotel.

Kegiatan publikasi yang dilakukan PR Sofyan Hotel Cut Meutia efektif, terbukti dengan meningkatnya penjualan dan jumlah pengunjung, serta kenaikan followers, banyaknya view dan banyaknya likes di media sosial Sofyan Hotel Cut Meutia. Strategi push dilakukan melalui promosipromosi dan diskon di media cetak, media digital, website resmi Sofyan Hotel serta melakukan aktivasi di dalam hotel, memberikan member card bagi customer yang loyal. Strategi pass dilakukan melalui kegiatan CSR, kolaborasi dengan komunitas dan brand, mengadakan event, bazaar, pameran, acara mini talkshow dan seminar di dalam hotel dan berkerja sama dengan Baznas untuk melakukan kegiatan amal sebagai wujud kepedulian Sofyan Hotel kepada masyarakat.

Kendala dalam proses menjalankan strategi marketing public relations seperti menangani komplain, mengorganisir kegiatan event PR, pelayanan yang kurang maksimal persaingan bisnis yang sejenis terbatasnya fasilitas dan sarana hotel. Solusi yang digunakan Sofyan Hotel Cut Meutia untuk meminimalisir kendala yang terjadi yaitu mengikuti perkembangan yang sedang trendy, mengembangkan pengetahuan staff, manajemen dan pimpinan perusahaan agar terus mengetahui perkembangan pasar, memaksimalkan dan meningkatkan pelayanan hotel dengan mendengarkan saran, masukan dan kritik dari customer untuk segera memperbaikinya dan menambahkan peralatan dan perlengkapan di kamar Sofyan Hotel Cut Meutia.

\section{DAFTAR PUSTAKA}

[1] Ali, D. S. (2017). Marketing Public Relations - Diantara Penjualan Dan Pencitraan. Yogyakarta: Deepublish.

[2] Bandur, A. (2016). Penelitian Kualitatif- Metodologi, Desain dan Teknik Analisis Data dengan NVivo 11 Plus. Jakarta: Mitra Wacana Media.

[3] Griffin, J. (2016). Customer Loyalty Menumbuhkan \& Mempertahankan Kesetiaan Pelanggan. Jakarta: Erlangga.

[4] Maryam. (2017, Oktober). Strategi Marketing Public Relations Dalam Meningkatkan Jumlah Tamu Hotel Pantai Marina Bengkalis. JOM FISIP, Vol.4 No.2, 1-19.

[5] M. Cutlip, S., H. Center, A., \& M. Broom, G. (2006). Effective Public Relations Edisi Kesembilan. Jakarta: Prenadamedia Group.

[6] Miles, M., Hubberman, A., \& Saldana, J. (2014). Qualitative Data Analysis, A Methods Sourcebook (Edition3 ed.). USA: Sage Publications. Terjemahan Tjejep Rohindi Rohidi, UIPress.

[7] Moleong, L. J. (2016). Metodologi Penelitian Kualitatif Edisi Revisi. Bandung: PT. Remaja Rosda Karya.

[8] Puspaningrum, A. (2017). Kepuasan Dan Loyalitas Pelanggan (Kajian Perilaku Pelanggan Hypermarket). Malang: Media Nusa Creative.

[9] Ruslan, R. (2016). Manajemen Public Relations \& Media Komunikasi (konsepsi dan Aplikasi) (Cetakan ke-11 ed.). Jakarta: PT Raja Grafindo Persada.

[10] Sari, A. A. (2017). Dasar-Dasar Public Relations Teori dan Praktik. Yogyakarta: Deepublish.

[11] Soemirat, S., \& Ardianto, E. (2012). Dasar-Dasar Public Relations. Bandung: PT. Remaja RosdaKarya. 
[12] Soemirat, S., \& Ardianto, E. (2017). Dasar-Dasar Public Relation. Bandung: PT Remaja Rosdakarya.

[13] Sugiyono. (2015). Metode Penelitian Kuantitatif, Kualitatif, dan R\&D. Bandung: Alfabeta.

[14] Suryanto. (2015). Pengantar Ilmu Komunikasi. Bandung: CV Pustaka Setia. 